\title{
Research Note: \\ Determination of soil hydraulic properties using pedotransfer functions in a semi-arid basin, Turkey
}

\author{
Mustafa Tombul ${ }^{1}$, Zuhal Akyürek ${ }^{2}$ and A. Ünal Sorman ${ }^{3}$ \\ ${ }^{1}$ Anadolu University, Civil Engineering Department, 26470 Eskisehir, Turkey \\ ${ }^{2}$ METU Geodetic and Geographic Information Technologies Division, 06531 Ankara, Turkey \\ ${ }^{3}$ METU Civil Engineering Department, 06531 Ankara, Turkey
}

Email for corresponding author: mtombul@anadolu.edu.tr

\begin{abstract}
Spatial and temporal variations in soil hydraulic properties such as soil moisture $\theta(h)$ and hydraulic conductivity $K(\theta)$ or $K(h)$, may affect the performance of hydrological models. Moreover, the cost of determining soil hydraulic properties by field or laboratory methods makes alternative indirect methods desirable. In this paper, various pedotransfer functions (PTFs) are used to estimate soil hydraulic properties for a small semi-arid basin (Kurukavak) in the north-west of Turkey. The field measurements were a good fit with the retention curve derived using Rosetta SSC-BD for a loamy soil. To predict parameters to describe soil hydraulic characteristics, continuous PTFs such as Rosetta SSC-BD (Model H3) and SSC-BD- $\theta_{33} \theta_{1500}$ (Model H5) have been applied. Using soil hydraulic properties that vary in time and space, the characteristic curves for three soil types, loam, sandy clay loam and sandy loam have been developed. Spatial and temporal variations in soil moisture have been demonstrated on a plot and catchment scale for loamy soil. It is concluded that accurate site-specific measurements of the soil hydraulic characteristics are the only and probably the most promising method to progress in the future
\end{abstract}

Keywords: soil hydraulic properties, soil characteristic curves, PTFs

\section{Introduction}

Soil hydraulic properties are important in quantifying the physical processes active in the unsaturated zone of soils. The hydrological models used to estimate the contributions of precipitation to runoff, infiltration and evapotranspiration require input parameters governing the retention and transport of water in the soil and the spatial and temporal variabilities in these hydraulic characteristics. Water flow in the soil is described mathematically by Richard's equation involving soil water pressure potential (h), volumetric water content $(\theta)$ and hydraulic conductivity (K). The functions of soil water retention $\theta(\mathrm{h})$ and of hydraulic conductivity $K(\theta)$ or $K(h)$ are usually referred as the unsaturated soil hydraulic properties (Romano and Santini, 1997). In addition, topography, geological formation, soil structure, vegetation, catchment area and land-use characteristics may all affect the rainfall-runoff relationship. The effects of spatial variability of soil properties and of rainfall on spatially averaged infiltration rates have been modelled semi-analytically by Sivapalan and Wood (1986) in a study of saturation excess and infiltration excess mechanisms on runoff production. The effect of the capillary fringe on surface contributing area dynamics was also taken into account by Sivapalan et al. (1987). The soil hydraulic properties required are the retention characteristics, expressed by the moisture-suction relation of the soil, and the transport characteristics expressed by the conductivity and suction relation of the soil.

Soil hydraulic characteristics can be determined by field or laboratory methods, both of which can be costly in time and labour: retreiving data including high-resolution soil moisture maps (over 10000 point measurements at up to 2060 sites) from the Tarrawarra catchment in south-eastern Australia, required 250 person days in the field and 100 person days in the laboratory (Western and Grayson, 1998). Zehe and Blöschl (2004) used 50 and 61 measurement points 
at the plot and catchment scales, respectively, and considered their soil moisture data to be fairly detailed, much more so than in most hydrological studies. The importance of the soil hydraulic properties led researchers to develop indirect methods of determining unsaturated and saturated hydraulic conductivity and water retention parameters. The indirect methods are pore-size distribution models, inverse methods and pedotransfer functions (Schaap, 1999; Schaap et al., 2001).

Pore-size distribution models estimate unsaturated hydraulic conductivity from the distribution, connectivity and tortuosity of pores (Mualem, 1976; Brooks and Corey, 1964; van Genuchten, 1980). Inverse methods (Sobieraj et al., 2001) combine a numerical model of the Richards' equation with an optimisation algorithm to estimate the unknown parameters from time series of measurements of infiltration, water content and/or pressure head. Pedotransfer functions (PTFs) are statistical regressions between soil properties (Bouma, 1989; Hamblin, 1991) and estimate hydraulic properties from soil physical properties such as soil texture, bulk density, organic matter content and water retention. Schaap (1999) categorised PTFs into three main groups:

(i) class PTFs, exemplified by Wösten et al. (1995) and Leij et al. (1996), are based on the assumption that similar soils exhibit similar hydraulic properties.

(ii) continuous PTFs provide continuously varying estimates of hydraulic properties across the textural triangle through linear or nonlinear regression models (Rawls et al., 1992).

(iii) Neural network analysis-derived PTFs have recently been developed to improve the predictions of emprical PTFs (Schaap et al., 1998).

Sobieraj et al. (2001) evaluated the performance of nine published PTFs for estimating saturated hydraulic conductivity in modelling the stormflow generated in a rainforest in the Rio Pichis Valley in the Selva Central of Peru. Wöstern et al. (2001) tested 21 PTFs for their reliability against the measurements in Oklahoma.

In this paper, the performances of various published PTFs in estimating the soil hydraulic properties of Kurukavak, a small semi-arid basin in north-western Turkey, are compared with field and laboratory records. The retention curves relate to the soil classes in the basin. In addition, the final concern is to examine how soil moisture varies spatially and temporally at plot and catchment scales.

\section{Materials and methods}

STUDY AREA AND DATA

Kurukavak Creek, a sub-basin of the Sakarya basin in NW Turkey, has a drainage area of $4.25 \mathrm{~km}^{2}$ and ranges in altitude from $830 \mathrm{~m}$ to $1070 \mathrm{~m}$. The basin is equipped with three rain gauges ( $\mathrm{R} 1, \mathrm{R} 2$, and $\mathrm{R} 3$ ) and one runoff recording station (H1) (Fig. 1).

Field measurements and mapping of soil properties (unsaturated hydraulic conductivity, saturated hydraulic conductivity, soil moisture values, and soil texture) were affected in this basin. A digital elevation model (DEM) with $30 \mathrm{~m}$ square grid was derived from the triangular irregular network modelling of the elevation map. The topographic index $\ln \left(\frac{\sum a_{i}}{\tan \beta}\right)$, a function of flow accumulation $\left(\mathrm{a}_{\mathrm{i}}\right)$ and the slope of the landscape ( $\tan \beta$ ) (Beven and Kirby, 1979), was then extracted from the DEM (Fig. 2). The topographic index was described as minimum $(<5.4)$, mean (5.4-6.8) and maximum $(>6.8)$ according to the natural break classification. This method identifies breakpoints between classes using a statistical formula (Jenks Optimization). The number of samples collected from each topographic index class was adequate considering the accessibility of the sample locations. The brush and forest areas (Fig. 3b) were excluded from the analysis because of their inaccessibility in the basin, so that only the pasture and non-irrigated landuse types were considered; they covered $2.57 \mathrm{~km}^{2}$ of the study area. Thus, a total of 126 samples were collected to represent text classes from the field for three soil types, namely sandy loam (46), loam (29) and sandy clay loam (51). The soil moistures at pressures of $330 \mathrm{~cm}$ (33 bar) and $15000 \mathrm{~cm}$ (1500 bar) were determined in addition to volumetric saturation moisture contents $\left(\theta_{\mathrm{s}}\right)$. The saturated hydraulic conductivity $\left(\mathrm{K}_{\mathrm{s}}\right)$ for 11 undisturbed soil samples was also measured in the laboratory and the texture classes based on these measurements are presented in Table 1.

The distribution of soil particles was obtained and the soil was classified according to the methods of the US Department of Agriculture (USDA). The sample sites were located by GPS and noted on the map of soil classes, obtained from the General Directorate of Village Affairs. Some of the soil classes at sample locations did not match the main soil groups; some of the loam and sandy clay loam soil samples were found in the sandy loam soil group, some of the sandy loam soil samples were found in sandy clay loam soil group and some of the sandy clay loam soil samples were found in loam soil group. Figure 3 a shows the locations of the sample sites on the soil map and the land-use types within the basin are presented in Fig. 3b. 
Mustafa Tombul, Zuhal Akyürek and A. Ünal Sorman

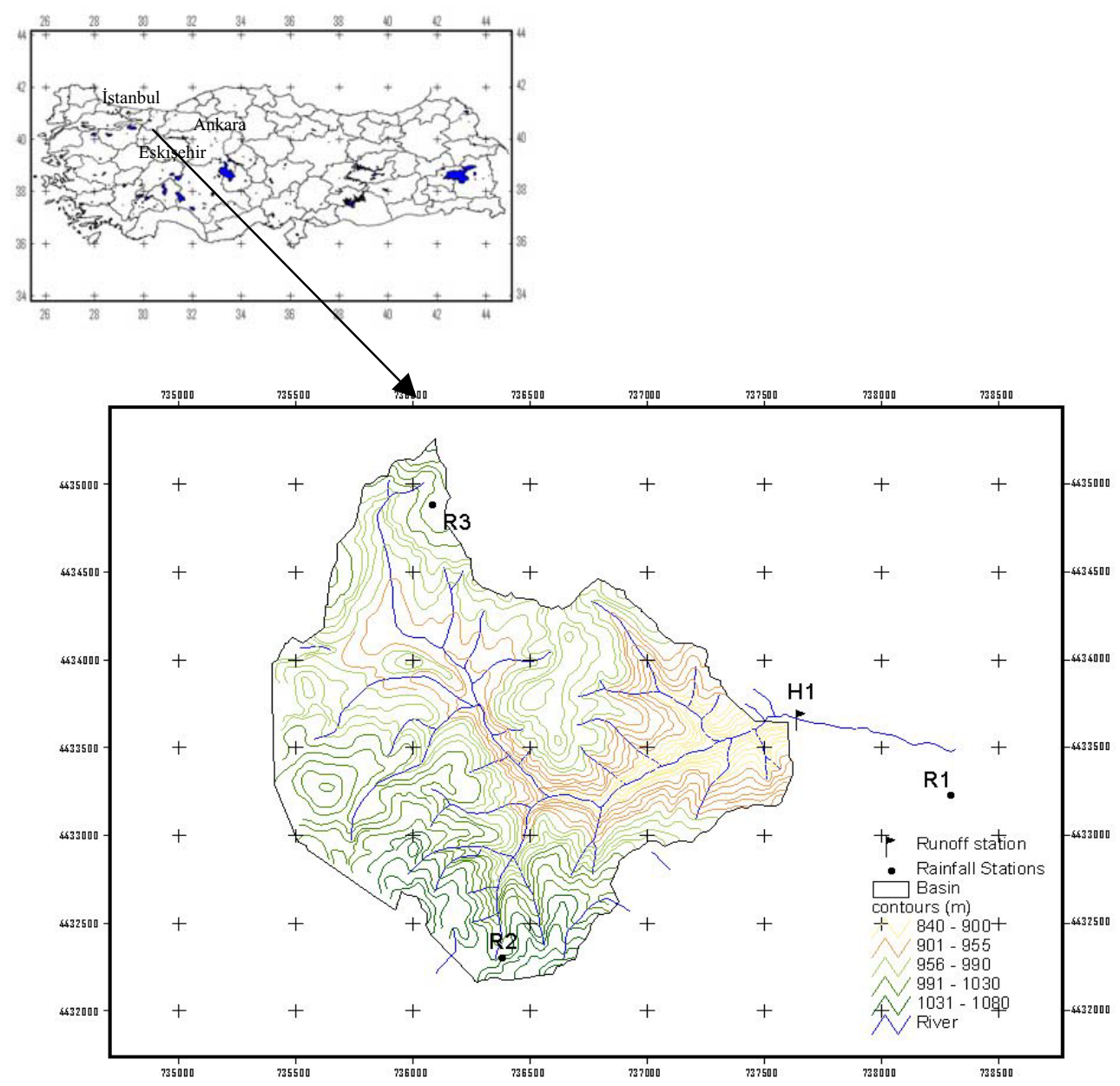

Fig. 1. Location of the study area in Turkey, the elevation contours and the recording stations in the basin

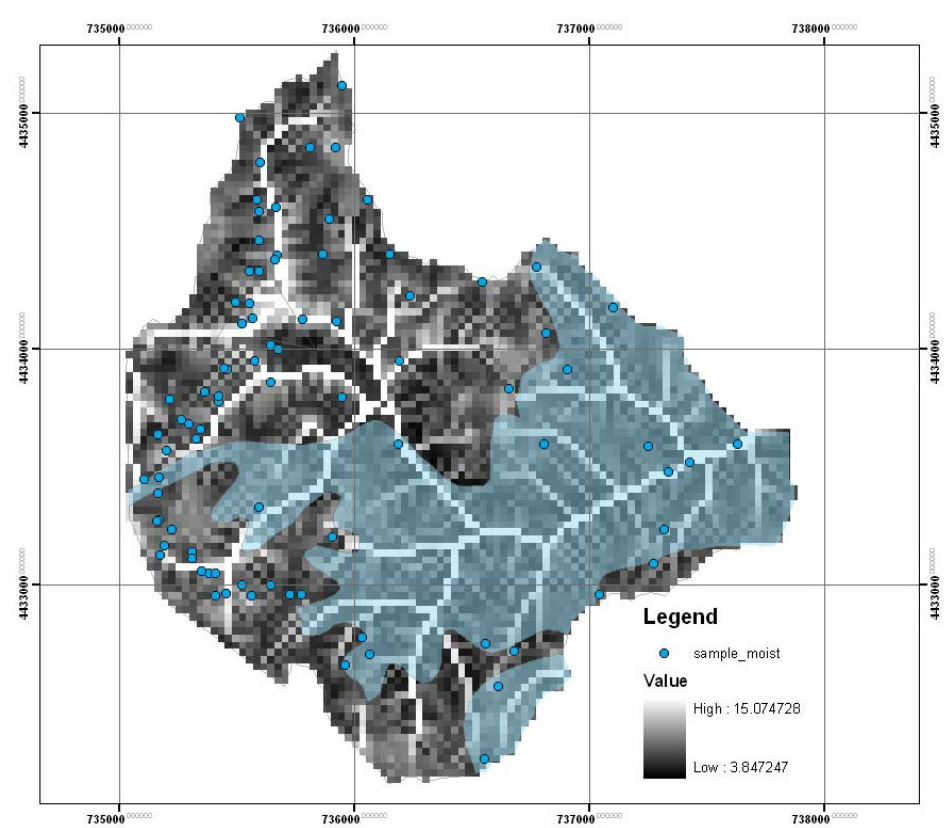

Fig. 2. The topographic index derived from DEM and the location of some of the field measurements (Brush and forest areas are masked). 
Table 1. Texture classes based on measured values

\begin{tabular}{|c|c|c|c|c|}
\hline$\theta_{\text {sat. }}\left(\mathrm{cm}^{3} \mathrm{~cm}^{-3}\right)$ & $\theta_{33}\left(\mathrm{~cm}^{3} \mathrm{~cm}^{-3}\right)$ & $\theta_{1500}\left(\mathrm{~cm}^{3} \mathrm{~cm}^{-3}\right)$ & Bulk density $\left(\mathrm{g} \mathrm{cm}^{-3}\right)$ & $K_{\text {sat. }}(11) *(\mathrm{~cm} \mathrm{hr})$ \\
\hline \multicolumn{5}{|c|}{ SANDY LOAM (46 samples) } \\
\hline 0.46 & 0.338 & 0.168 & 1.43 & $1.02(2)^{*}$ \\
\hline \multicolumn{5}{|l|}{ LOAM (29 samples) } \\
\hline 0.47 & 0.362 & 0.172 & 1.34 & $0.95(7)^{*}$ \\
\hline & \multicolumn{4}{|c|}{ SANDY CLAY LOAM (51 samples) } \\
\hline 0.47 & 0.345 & 0.186 & 1.41 & $0.86(2)^{*}$ \\
\hline
\end{tabular}
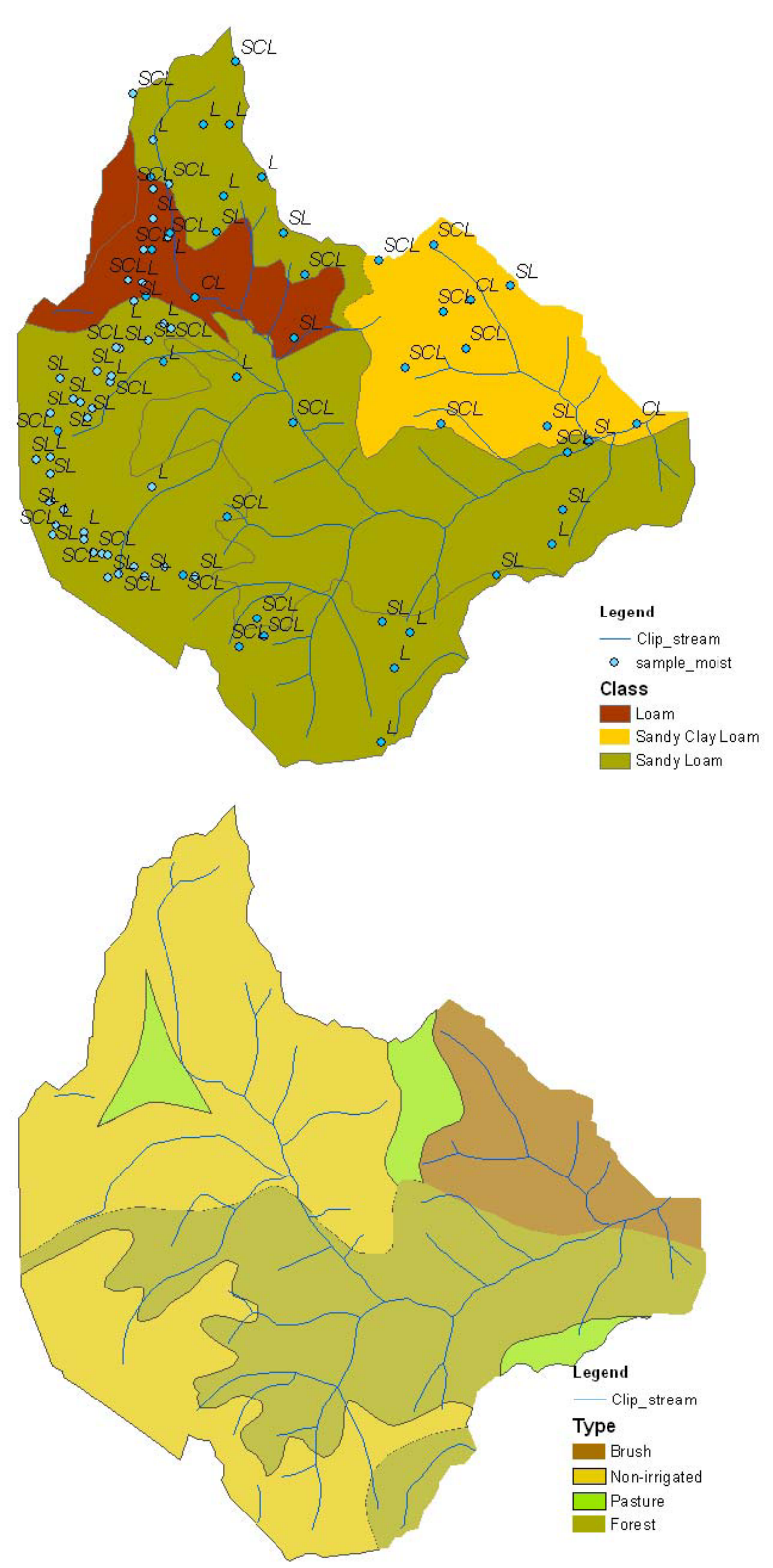

Fig. 3. The soil map with the location of soil samples (top), land use map of the basin (bottom)

\section{PREDICTION OF THE WATER RETENTION CHARACTERISTICS AT SAMPLE POINTS}

For predicting the water retention characteristics at specific points, the second group PTF, (Gupta and Larson 1979) was used. Those are early PTFs, with the general form:

$$
\begin{array}{r}
\theta_{\mathrm{h}}=\mathrm{a}^{*} \operatorname{sand}(\%)+\mathrm{b}^{*} \operatorname{silt}(\%)+\mathrm{c}^{*} \operatorname{clay}(\%)+\mathrm{d}^{*} \text { organic } \\
\text { matter }(\%)+\mathrm{e}^{*} \text { dry bulk density }+\mathrm{x}^{*} \text { variable X }
\end{array}
$$

where $\theta_{h}$ is the water content at pressure head $h$ and $a, b, c$, $\mathrm{d}$ and e are regression coefficients. Variable $\mathrm{X}$ is any other basic soil property that is measurable. The coefficients ' $a$ ' through ' $x$ ' are determined by regression of $\theta$ at, for example, $\mathrm{h}=-40 \mathrm{kPa}$ versus relevant soil properties. In these prediction equations, a wide range of samples (20574 in all) was considered, collected from North America as well as Europe. In addition, saturated hydraulic conductivity was measured for 235 soil samples. Wösten et al. (2001) consider the main advantage of the indirect approach is that fairly accurate predictions can be expected at specific points along water retention relations. Another advantage is that it offers insight into which soil properties are relevant. Hence, the model consists of various soil properties which require specifically point soil data.

In the present study, because the measured values differ from those used to develop the equation, the reliability of pedotransfer functions was evaluated using root mean square error (RMSE) statistics;

$$
R M S E=\sqrt{\frac{1}{N} \sum_{i=1}^{N}\left(\zeta-\zeta^{\prime}\right)^{2}}
$$

The symbols $\zeta$ and $\zeta^{\prime}$ denote values of measured and estimated $\theta(h), \log K_{s}$, or $\log K(h)$ respectively; $N$ is the number of samples (Schaap and van Genuchten., 2001). For the three soil types, the RMSE of volumetric water contents ranges from 0.025 to $0.088 \mathrm{~cm}^{3} \mathrm{~cm}^{-3}$ (Table 2). 
Table 2. RMSE for measured and predicted water retention parameters from Gupta and Larson (1979) PTFs

\begin{tabular}{llccc}
\hline \multirow{2}{*}{$\begin{array}{l}\text { Number of } \\
\text { samples }\end{array}$} & Soil type & $\theta_{\text {sat }} R M S E\left(\mathrm{~cm}^{3} \mathrm{~cm}^{-3}\right)$ & $\begin{array}{l}\text { Water retention parameters } \\
\theta_{33} R M S E\left(\mathrm{~cm}^{3} \mathrm{~cm}^{-3}\right)\end{array}$ & $\theta_{1500} R M S E\left(\mathrm{~cm}^{3} \mathrm{~cm}^{-3}\right)$ \\
\hline 46 & & 0.088 & 0.087 & 0.037 \\
29 & Sandy loam & 0.051 & 0.060 & 0.028 \\
51 & Loam & 0.086 & 0.069 & 0.025 \\
\hline
\end{tabular}

\section{DETERMINATION OF SOIL HYDRAULIC CHARACTERISTICS}

In predicting the parameters to describe the complete hydraulic characterisitcs, PTFs of Type 3 were used. Since in contrast to Type 2 , Type 3 PTFs usually predict parameters in models describing the complete $\theta-h-K$ relationship. The determinations were performed using the PTFs provided by Rosetta (Schaap and Leij, 2000); this package offers five pedotransfer functions (PTFs) that allow the prediction of the hydraulic properties from limited or more extended sets of input data (Schaap et al., 1998). The first model (H1) uses USDA soil textural classes. The second model (H2) uses sand, silt and clay percentages as input. The third model (H3) adds bulk density to sand, silt and clay percentages. The fourth model (H4) uses sand, silt and clay percentages, bulk density and a water retention point at $330 \mathrm{~cm}$ suction $(33 \mathrm{kPa})$. The fifth model (H5) adds the water content at $15000 \mathrm{~cm}$ suction $(1500 \mathrm{kPa})$ to the input variables of the fourth model.

The first model, based on a lookup table, provides class average hydraulic parameters for each USDA soil textural class. The other four models ( $\mathrm{H} 2$ to $\mathrm{H} 5)$ are based on neural network analyses and provide more accurate predictions when measurements of more input variables are available. In addition to the hierarchical approach, a model (Schaap and Leij, 2000) that allows the prediction of unsaturated hydraulic conductivity parameters from fitted van Genuchten (1980) retention parameters was used to explore the variation of $\mathrm{K}$ with $\theta$. It is also possible to estimate the van Genuchten (1980) water retention parameters $\left(\theta_{\mathrm{r}}, \theta_{\mathrm{s}}, \alpha\right.$, $\mathrm{n})$, the saturated hydraulic conductivity $\left(\mathrm{K}_{\mathrm{s}}\right)$ and the unsaturated hydraulic conductiva:ity $\mathrm{K}(\mathrm{h})$ based on Mualem's pore pressure distribution model.

The function for $\mathrm{q}(\mathrm{h})$ is:

$$
\frac{\left(\theta(\mathrm{h})-\theta_{\mathrm{r}}\right)}{\left(\theta_{\mathrm{s}}-\theta_{r}\right)}=\frac{1}{\left[1+(\alpha h)^{n}\right]^{m}}
$$

which can be written as:

$$
S_{e}=\frac{\theta(h)-\theta_{r}}{\theta_{s}-\theta_{r}}=\left[1+(\alpha \times h)^{n}\right]^{1 / n-1}
$$

where $\theta$ is the volumetric water content in $\mathrm{cm}^{3} \mathrm{~cm}^{-3}$ at suction head $\mathrm{h}$ in $\mathrm{cm}$. The other parameters $\theta_{\mathrm{r}}$ and $\theta_{\mathrm{s}}$ are residual and saturated water contents in $\mathrm{cm}^{3} \mathrm{~cm}^{-3}$ respectively, $\alpha$ is related to the inverse of the air entry suction in $1 \mathrm{~cm}^{-1}$ and $n$ is a measure of pore size distribution with $\mathrm{m}=(1-1 / \mathrm{n})$ called the shape parameter.

The optimum soil water output parameters of Van Genuchten, determined from the PTFs provided by Rosetta, (Table 3) were introduced to predict the soil water

\begin{tabular}{|c|c|c|c|c|c|c|}
\hline & Model type & $\theta_{r}\left(\mathrm{~cm}^{3} / \mathrm{cm}^{3}\right)$ & $\theta_{s}\left(\mathrm{~cm}^{3} / \mathrm{cm}^{3}\right)$ & $\alpha(1 / \mathrm{cm})$ & $n$ & $K_{\text {sat. }}(\mathrm{cm} / \mathrm{hr})$ \\
\hline \multicolumn{7}{|c|}{ SANDY LOAM (46 samples) } \\
\hline \multirow[t]{2}{*}{$\mathrm{H} 3$} & 0.054 & 0.41 & 0.0230 & 1.420 & 1.22 & \\
\hline & H5 & 0.051 & 0.43 & 0.0067 & 1.450 & 0.58 \\
\hline \multicolumn{7}{|c|}{ LOAM (29 SAMPLES) } \\
\hline \multirow[t]{2}{*}{$\mathrm{H} 3$} & 0.065 & 0.42 & 0.0120 & 1.482 & 0.90 & \\
\hline & H5 & 0.058 & 0.44 & 0.0098 & 1.368 & 0.73 \\
\hline \multicolumn{7}{|c|}{ SANDY CLAY LOAM (51 samples) } \\
\hline \multirow[t]{2}{*}{$\mathrm{H} 3$} & 0.067 & 0.42 & 0.0171 & 1.411 & 0.89 & \\
\hline & H5 & 0.058 & 0.43 & 0.0089 & 1.331 & 0.49 \\
\hline
\end{tabular}

Table 3. Soil water output (van Genuchten) parameters using Rosetta 
characteristics for the three soil texture classes. However, these models predict the soil water characteristics in a broadly defined manner and do not provide site-specific information.

The PTF-derived $\mathrm{K}_{\mathrm{s}}$ estimates were compared with the measured $\mathrm{K}_{\mathrm{s}}$ values for each soil type. Rosetta SSC-BD$\theta_{33} \theta_{1500}$ (Model H5) underestimated $\mathrm{K}_{\mathrm{s}}$ values for all three soil groups. Rosetta SSC-BD overestimated $\mathrm{K}_{\mathrm{s}}$ values for sandy loam, but estimates for loam and sandy clay loam were reasonable. This indicates that texture and bulk density can be considered as good predictors of saturated hydraulic conductivity.

The maximum, minimum and mean values of $\theta(h)$ at $h=$ 330 and $15000 \mathrm{~cm}$ obtained from the models were compared with the field samples at the same pressures (Table 4). The results of these field measurements lay within the limits of the predicted values obtained by the $\mathrm{H} 3$ and $\mathrm{H} 5$ models at the two pressure levels except for $\theta_{33}$ for the sandy loam soil type.

\section{PRESSURE-WATER CONTENT RELATIONS}

The relationship between pressure head ( $h$ ) and volumetric water content $(\theta)$, the water retention curve, should be obtained for all relevant soil classes. The RETC (RETention Curve) computer program describes the hydraulic properties of unsaturated soils and may be used to fit several analytical models to the observed water retention and/or unsaturated hydraulic conductivity data. The soil water retention curve, $\theta(\mathrm{h})$, in the program can be represented by the equations of Brooks-Corey or van Genuchten, while the unsaturated hydraulic conductivity, $\mathrm{K}(\mathrm{h})$ or $\mathrm{K}(\theta)$, and diffusivity, $\mathrm{D}(\theta)$, functions are formulated in terms of the statistical pore-size distribution models of Mualem (1976). Closed-form expressions such as Eqns. (3) and (4) provide a consistent description of water retention and unsaturated hydraulic conductivity curves and are convenient for use in numerical models simulating saturated flow.

In this study, for a loamy soil, field measurements of volumetric water content with respect to pressure head were obtained from a soil moisture probe with its data logger system, placed $30 \mathrm{~cm}$ below the soil surface to measure temporal variations in the soil suction head $(\mathrm{cm})$ from September 30, 2001 (Julian day 273) until February 9, 2002 (Julian day 40). Rosetta SSC-BD (Model H3) was used to derive the retention curve for the loamy soil at a plot scale. The unsaturated hydraulic properties $\theta(\mathrm{h})$ at two levels of pressure head were determined by the van Genuchten (1980) model using soil water parameters derived from Rosetta. Because the field measurements fitted the derived retention curve (Fig. 4a) well, the characteristic curves for the sandy (a)

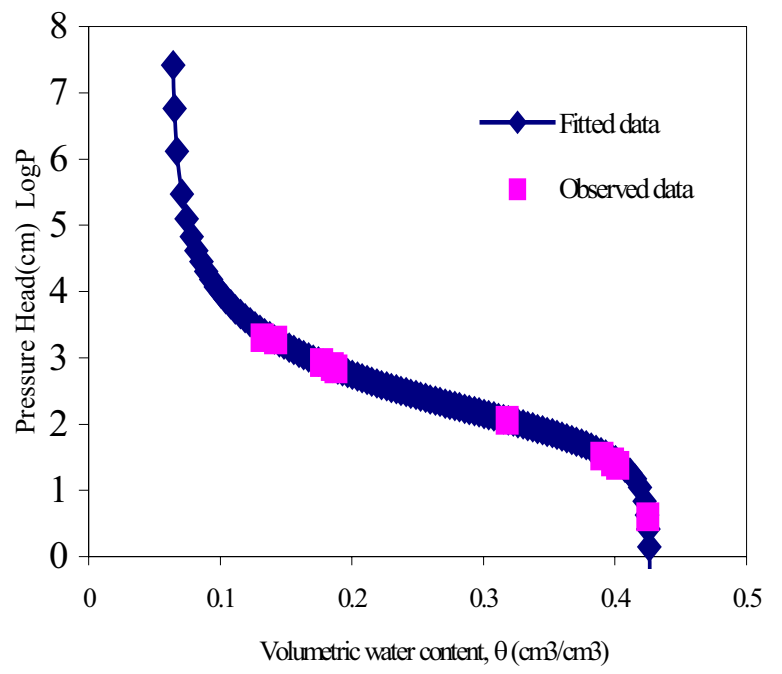

(b)

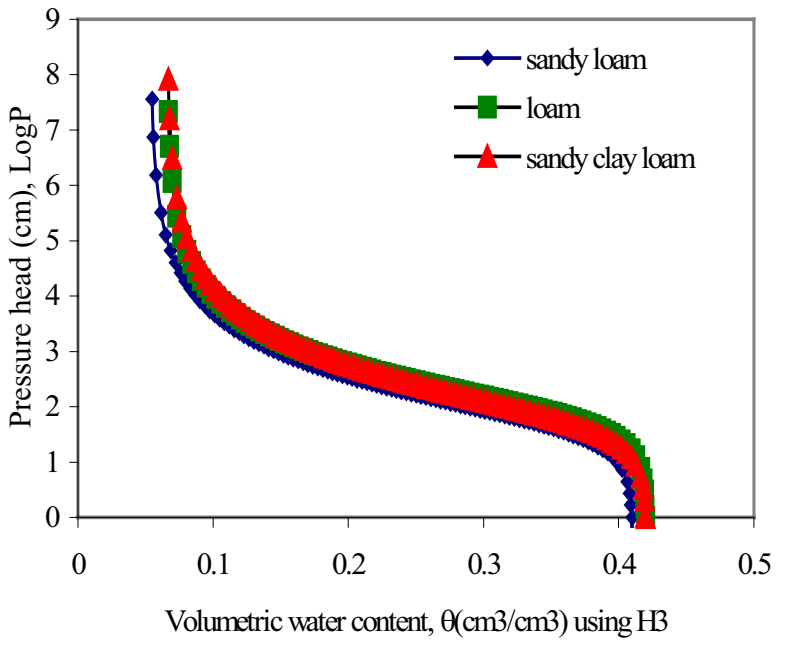

(c)

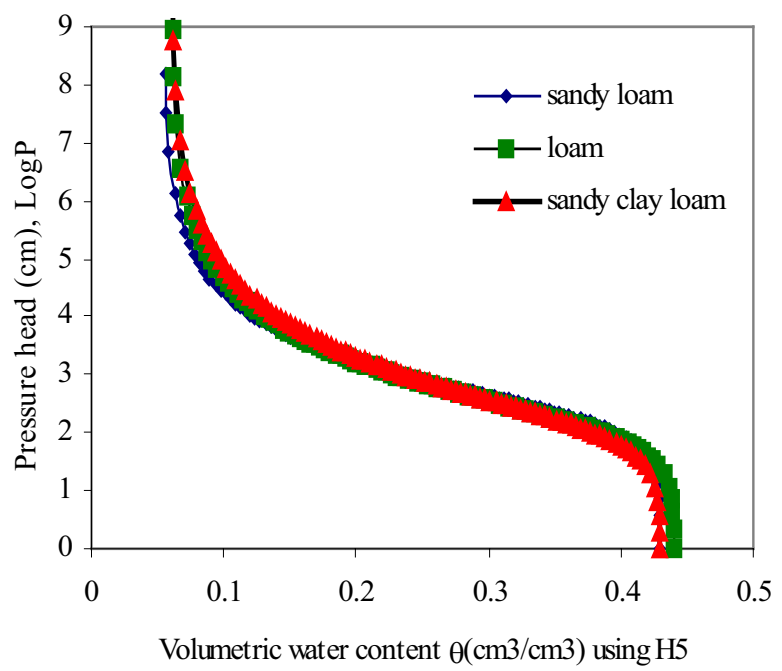

Fig. 4. (a) observed and fitted water retention for loamy soil (b) Water retention curves for three soil types derived by using $\mathrm{H3}$ model (c) Water retention curves for three soil types derived by using H5 model. 
Table 4. Comparison with field records of the unsaturated hydraulic properties $\theta$ (h) at two levels of pressure head determined by Van Genuchten (1980) model using soil water parameter derived from Rosetta.

\begin{tabular}{|c|c|c|c|c|}
\hline$\theta(h)$ & Field data for $\theta(h)$ mean & Rosetta Model Type & \multicolumn{2}{|c|}{$\begin{array}{l}\text { Van Genuchten (1980) } \\
\text { Model } \theta(h)\end{array}$} \\
\hline \multicolumn{5}{|c|}{ SANDY LOAM (46 samples) } \\
\hline \multirow[t]{6}{*}{$\theta_{33}$} & Max 0.449 & $\mathrm{H} 3$ & Max & 0.388 \\
\hline & & & Min & 0.265 \\
\hline & Min 0.257 & & Mean & 0.346 \\
\hline & & $\mathrm{H} 5$ & $\operatorname{Max}$ & 0.444 \\
\hline & Mean 0.338 & & Min & 0.360 \\
\hline & & & Mean & 0.404 \\
\hline \multirow{6}{*}{$\theta_{1500}$} & Max 0.262 & $\mathrm{H} 3$ & Max & 0.143 \\
\hline & & & Min & 0.069 \\
\hline & Min 0.126 & & Mean & 0.126 \\
\hline & & $\mathrm{H} 5$ & $\operatorname{Max}$ & 0.306 \\
\hline & Mean 0.168 & & Min & 0.152 \\
\hline & & & Mean & 0.208 \\
\hline \multicolumn{5}{|c|}{ LOAM (29 samples) } \\
\hline \multirow[t]{6}{*}{$\theta_{33}$} & Max 0.440 & $\mathrm{H} 3$ & Max & 0.428 \\
\hline & & & Min & 0.347 \\
\hline & Min 0.304 & & Mean & 0.387 \\
\hline & & H5 & $\operatorname{Max}$ & 0.448 \\
\hline & Mean 0.362 & & Min & 0.328 \\
\hline & & & Mean & 0.421 \\
\hline \multirow[t]{6}{*}{$\theta_{1500}$} & Max 0.251 & $\mathrm{H} 3$ & Max & 0.194 \\
\hline & & & Min & 0.142 \\
\hline & Min 0.12 & & Mean & 0.154 \\
\hline & & H5 & Max & 0.276 \\
\hline & Mean 0.172 & & Min & 0.167 \\
\hline & & & Mean & 0.215 \\
\hline \multicolumn{5}{|c|}{ SANDY CLAY LOAM (51 samples) } \\
\hline \multirow[t]{6}{*}{$\theta_{33}$} & Max 0.410 & $\mathrm{H} 3$ & Max & 0.417 \\
\hline & & & Min & 0.332 \\
\hline & Min 0.280 & & Mean & 0.378 \\
\hline & & H5 & Max & 0.444 \\
\hline & Mean 0.345 & & Min & 0.341 \\
\hline & & & Mean & 0.412 \\
\hline \multirow[t]{6}{*}{$\theta_{1500}$} & Max 0.268 & $\mathrm{H} 3$ & Max & 0.196 \\
\hline & & & Min & 0.149 \\
\hline & Min 0.139 & & Mean & 0.155 \\
\hline & & H5 & Max & 0.263 \\
\hline & Mean 0.186 & & Min & 0.172 \\
\hline & & & Mean & 0.214 \\
\hline
\end{tabular}


loam and the sandy clay loam were also derived using the Rosetta SSC-BD (Model H3) and SSC-BD- $\theta_{33} \theta_{1500}$ (Model H5) (Fig. 4.b-c).

TEMPORAL AND SPATIAL VARIATION OF SOIL MOISTURE AT A PLOT AND OVER A CATCHMENT

Since soil moisture is highly variable in space and time, in hydrological models the variability resulting from many integrated processes must be studied on a catchment or a plot scale using point measurements, soil courses, moisture profiles and sensors (Zehe and Blöschl, 2004). The temporal variation of the soil suction head $(\mathrm{cm})$ from September 30 , 2001 until February 9, 2002 was recorded by the soil moisture sensor and these soil suction head values were converted to volumetric moisture content. The volumetric soil moisture values measured at several locations in the loamy soil class in the basin were used to represent the spatial variation of moisture content. Using the van Genuchten parameters (Table 3), volumetric soil moisture values on a catchment scale were obtained from Model 3 (Fig. 5). The comparison of plot values with catchment scale field measurements of soil moisture on different Julian days, indicates variations due to uncertainties resulting from topographical factors (slope, distance to stream channel) and land-use type features. The soil moisture values for loamy soil (47 samples) averaged at minimum $(<5.4)$ and maximum $(>6.8)$ topographical index values were plotted on the same figure to present the spatial variation in soil moisture for the same soil type.

\section{Discussion}

The soil hydraulic properties needed in this analysis were the retention characteristics expressed by the moisturesuction relation for the soils and transport characteristics expressed by the conductivity and suction relation for the soil. PTFs developed from regional databases give good results in regions with similar soil and landscape history (Wöstern et al., 2001). Since there is no Turkish national database of measured soil hydraulic characteristics, PTFs have yet to be developed in Turkey. Therefore, various empirically derived PTFs, published elsewhere, were applied to the Kurukavak basin, to compare their performance with field measurements of hydraulic conductivity, soil moisture and bulk density.

The PTF proposed by Gupta and Larson (1979) for point prediction of water retention characteristics was used. Small values for the RMSEs of volumetric water contents were obtained for the three soil types, but this PTF was limited in

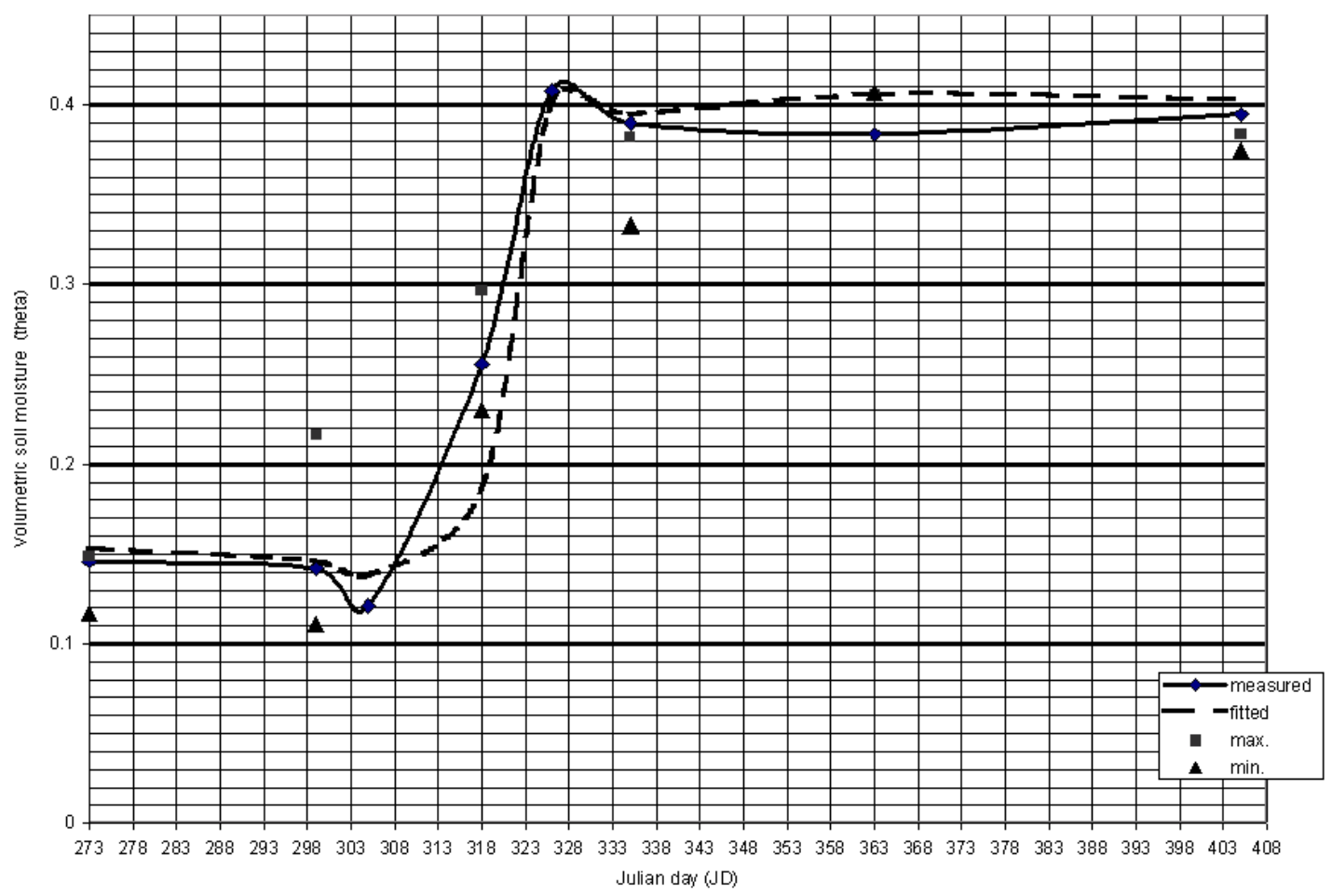

Fig. 5. Temporal variation of soil moisture at plot (derived from the soil moisture sensor) and catchment scale (derived by fitting PTF Model 3) with minimum and maximum field observations 
predicting the parameters used to describe the complete hydraulic characteristics. Therefore, Type 3 PTFs (Model H3) were used to predict parameters to describe the complete $\theta($ h) $-\mathrm{K}$ relationship. Table 3 shows that, although Rosetta SSC-BD (Model H3) overestimated $\mathrm{K}_{\mathrm{s}}$ values for a sandy loam soil, it performed well for a loam and a sandy clay loam. Rosetta SSC-BD- $\theta_{33} \theta_{1500} \theta$ (Model H5) underestimated $\mathrm{K}_{\mathrm{s}}$ values for all three soil groups. This suggests that bulk density may serve as a proxy for pore size distribution, one of the main determinants of $\mathrm{K}_{\mathrm{s}}$.

In predicting the pressure levels by PTFs, the field data obtained for $\theta(\mathrm{h}=330 \mathrm{~cm})$ and $\theta(\mathrm{h}=15000 \mathrm{~cm})$ proved to lie within the limits of the values predicted by the $\mathrm{H} 3$ and H5 modes at two pressure levels except for $\theta_{33}$ for sandy loam soil type. Also, their integration with the topographic index values defined by Beven and Kirkby (1979) was not significant according to the ANOVA (two way analysis of variance) test results. The characteristics of the sandy loam and sandy clay loam classes in the basin were similar to those for loam according to the water-retention characteristic curves relating pressure head to soil water content.

Considering the topographic index, catchment scale variability of soil moisture shows a large variation with respect to the field model $\mathrm{H} 3$, for which the model parameters are presented in Table 3. These models predict the soil water characteristics in a broadly defined way and do not show specific site information at a plot scale. Especially in the dry period of 2001, the observed field records at maximum and minimum topographic indices show large variations for moisture contents around $0.1 \mathrm{~m} \mathrm{~m}^{3} \mathrm{~m}^{-3}$ and $0.15 \mathrm{~m}^{3} \mathrm{~m}^{-3}$. On the other hand, the temporal variability of the moisture content derived from PTF model (Model H3) agrees closely with the measured plot scale soil moisture variability for the loam.

\section{Conclusions}

The soil hydraulic properties obtained from Rosetta SSCBD (Model H3) overestimated $\mathrm{K}_{\mathrm{s}}$ values for sandy loam soil but, for loam and sandy clay loam, $\mathrm{K}_{\mathrm{s}}$ estimates of Rosetta SSC-BD were acceptable. The field measurements fitted the derived retention curve well using Rosetta SSC$\mathrm{BD}$ for the loam. The characteristic curves for the threesoil types, sandy loam, loam and sandy clay loam were also derived.

Hence, accurate site-specific measurements of soil hydraulic characteristics is probably the most promising method for the future. More soil sample data are needed to form the soil database in countries like Turkey, having no or few data on soil properties. Such a database can be used to assess the accuracy and reliability of point records on a larger scale to be considered representative of basins located within homogeneous soil texture zones.

In hydrological modelling, soil water storage is important in calculating actual evapotranspiration as a function of potential evapotranspiration. In most hydrological models, soil water storage is assumed constant but the spatial variability in derived soil water storage distribution indicates the need to use spatially distributed soil water storage in dry catchments, where the groundwater table is deep and runoff is generated from overland and subsurface flow (rapid flow) components. In later stages, similar unit response areas will be formed to insert their hydro-meteorological and soil hydraulic parameters as input to distributed models for runoff estimation with or without routing.

\section{Acknowledgement}

This work is supported by the Scientific Research Commission of Anadolu University (project number 000261). The authors are thankful for the financial support.

\section{References}

Beven, K.J. and Kirkby, M.J., 1979. A physically based variable contributing area model of basin hydrology. Hydrolog. Sci. Bull., 24, 43-69.

Bouma, J., 1989. Using soil survey data for quantitative land evaluation. Adv. Soil Sci., 9,177-213.

Brooks, R.H. and Corey, A.T., 1964. Hydraulic properties of porous media. Hydrol. Pab.3, Colorado State University, Fort Collins, USA. 27pp.

Gupta, S.C. and Larson, W.E., 1979. Estimating soil water characteristic from particle size distribution, organic matter percent, and bulk density. Water Resour. Res. 15,1633-1635.

Hamblin, A., 1991. Sustainable agricultural systems, What are the appropriate measures for soil structure? Aust. J. Soil Res., 29, 709-715.

Leij, F.J., Alves, W.J., van Genuchten, M.Th. and Williams, J.R.,1996. The UNSODA unsaturated soil hydraulic database, version 1.0. EPA Report EPA/600/R-96/095, EPA National Risk Management Laboratory, G-72, Cincinnati, OH, USA, http:// www.uss-sl.ars.usda.gov/MODELS/UNSODA.HTM

Mualem, Y., 1976. A new model predicting the hydraulic conductivity of unsaturated porous media. Water Resour. Res., 12, 513-522.

Rawls, W.J., Brakensiek, D.L. and Saxton K.E., 1992. Estimation of soil water properties. Trans. Amer. Soc. Agr. Eng., 25, 13161320.

Romano, N. and Santini, A., 1997. Effectiveness of using pedotransfer functions to quantify the spatial variability of soil water retention characteristics. J. Hydrol., 202, 137-157.

Sivapalan, M. and Wood, E., 1986. Effect of scale on infiltration response in spatially variable soils. In: Scale Problems in Hydrology, V.K Gupta, I. Rodrigez-Iturbe and Wood D. (Eds.), Reidel, Hingham, Mass. USA.

Sivapalan, M, Wood, E. and Beven K.J., 1987. On hydrologic similarity, 2 A scaled model of storm runoff production. Water Resour. Res., 23, 2266-2278. 
Schaap, M.G., Leij, F..J. and van Genuchten, M.Th., 1998. Neural network analysis for hierarchical prediciton of soil hydraulic properties. Soil Sci. Soc. Amer. J.,.62, 847-855.

Schaap, M.G., 1999. Rosetta Version 1.0. US Salinity Laboratory, USDA, ARS: Riverside, CA, USA. http:// www.ussl.ars.usda.gov/models/rosetta/rosetta.htm

Schaap, M.G. and Leij, F.J., 2000. Improved prediction of unsaturated hydraulic conductivity with the Mualem-van Genuchten Model. Soil Sci. Soc. Amer. J., 64, 843-851.

Schaap, M.G., Leij, F.J. and van Genuchten, M.Th., 2001. Rosetta: a computer program for estimating soil hydraulic parameters with hierarchical pedotransfer functions. J. Hydrol., 251, 163176

Sobieraj, J.A., Elsenbeer, H. and Veressy, R.A., 2001. Pedotransfer functions for estimating saturated hydraulic conductivity implications for modeling stormflow generation. J. Hydrol., 251, 202-220 van Genuchten, M.T., 1980. A closed form equation for predicting the hydraulic conductivity of unsaturated soils. Soil Sci. Soc. Amer. J., 44, 892-901.

Western, A.W. and Grayson, R.B., 1998. The Tarrawarra data set: Soil moisture patterns, soil characteristics, and hydrological flux measurements. Water Resour. Res., 34, 2765-2768.

Wösten, J.H.M., Finke, P.A. and Jansen, M.J.W., 1995. Comparison of class and continuous pedotransfer functions to generate soil hydraulic characteristics. Geoderma, 66, 227-237.

Wösten, J.H.M., Pachepsk, Y.A. and Rawls, W.J., 2001. Pedotransfer functions: bridging the gap between available basic soil data and missing soil hydraulic characteristics. J. Hydrol., 251, 123-150.

Zehe, E. and Blöschl, G., 2004. Predictability of hydrologic response at the plot and catchment scales: Role of initial conditions. Water Resour. Res., 40, W10202, doi:10.1029/ 2003 WR002869. 